\title{
Culinary Crossing of Food Contact Materials with Emphasis on Endocrine Disruptors: A Review of Exposure, Effects and Risk Mitigation
}

\author{
Sarika Chhabria Talreja \\ Research Scholar, Department of Chemistry, \\ GuruNanak Khalsa College, Matunga, Mumbai 400019
}

\begin{abstract}
Food and beverages can be very aggressive chemical milieu interacting strongly with the materials they are placed in contact. The chemical partitioning from packaging polymers into food is called Leaching or Migration. A plethora of plastics like Polypropylene, Polystyrene Polycarbonates etc. have been conventionally used for food packaging. To make plastics more utilitarian, low molecular weight additives viz. Plasticizers, Antioxidants and Stabilizers are added. Infinitesimal bits of these additives may potentially leach into food during cooking or storage.
\end{abstract}

Recent health controversies have spawned new discussions about rampant use of detrimental polymeric food packaging products. Research scientists, health enthusiasts and regulatory agencies have now become concerned about consumer protection from the resulting food toxicity.

The present study attempts to focus on the issue of culinary crossing of Food Contact Materials (FCMs) with emphasis on endocrine disruptors like Bisphenol A (BPA), Phthalates etc. used extensively in Polycarbonate plastics. It aims at creating awareness about leaching of FCMs that have long been an underestimated source of food contamination and toxicity while reviewing its exposure, effects and risk mitigation strategies. The present study also warrants an assessment of the whole migrate toxicity of food packaging materials, taking into account all the sensitive population groups.

Keywords: Bisphenol A, Chemical milieu, Culinary Crossing, Leaching, Migrate toxicity

\section{Introduction}

Food and beverages can be very aggressive chemical milieu interacting strongly with FCMs. These chemicals may impart a taint and odor to the food, negatively affecting its quality and are harmful if ingested in substantial quantities. This chemical partitioning from the packaging materials into food is called Leaching or Migration. The term Migration refers to the diffusion of substances from a zone of higher concentration to that of a lower concentration.

1.1 Historical Overview: For millennia, humans stored their food in containers found in nature - dried gourds, shells, hollow logs, leaves, basket, pottery etc. This caused an increased susceptibility of food materials to the bacterial contamination which led to a plethora of food wastage. The evolution of art and science of food packaging from those origins has been commendable as it improved food safety by alleviating bacterial contamination and extended the shelf life of products, which allowed for broader distribution and reduced wastage.

1.2 Present Scenario: Food packaging provides additional features viz; resealability, traceability, convenience, tamper evidence, display of product information as well as reuse or recycling features besides keeping foods safe from contamination and retaining their nutritional properties and sensory characteristics. Advances in food processing and packaging have played a vital role in every phase of food production and storage. Processing of food takes place in plastic equipment, besides packaging and shipping in plastic-lined boxes and cans. At home, leftovers are stored and reheated in plastic containers. 
Packaging has allowed access to many foods yeararound that otherwise could not be preserved (Sara Risch, 2009). It keeps the food supply safe; besides maintaining the benefits of processing thus enabling the foods to travel safely for long distances from their point of origin and still be wholesome at the time of consumption. However, infinitesimal bits of plastics get into our food from these containers. Therefore, besides energy consumption and material costs, heightened environmental consciousness as well as regulations on pollutants and waste disposal, packaging technology must also balance food protection (Marsh and Bugusu, 2007).

\section{Methodology}

The present study is based on the secondary data collected from various books, relevant research reports, Internet websites, Magazines, Newspapers. Periodicals, Research journals and related articles were used as predominant sources for gathering the information. Desk research was followed by scanning and reviewing literature on the subject and collating the data collected from relevant sources.

\section{Limitations}

Only polymer migrants are covered in the paper with emphasis on the Endocrine Disrupting Chemicals (EDCs). Other chemicals like Aluminum migrating through Aluminum foils, dyes like Benzidine leaching from newspapers through printing inks and Lead, migrating from glass bottles into food materials have not been covered.

\section{Literature Review}

Grob K. et al (2006) proposed that the amount of material migrating from polymeric packages into food is substantially higher than that contributed by pesticides and environmental pollutants.

Goulas et al (2000) examined the migration of plasticizer Di - (2-ethylhexyl) adipate i.e. DEHA from food grade Polyvinyl chloride film into hard and soft cheese and observed statistically significant differences in migration of DEHA between the cheese types. They found that the migration of DEHA depended on contact time, fat and moisture contents and consistency of cheese samples.

Latini G. et al (2004) reviewed the reproductive and developmental toxicity of phthalate esters used as plasticizers in enormous quantities for a variety of industrial uses in the formulation of plastics.

Thompson B. M and Grounds P. R (2005) analyzed the BPA concentrations in different canned foods by Gas Chromatography and Mass Spectrometry to study the exposure of adults to BPA from the consumption of canned and bottled food.

Lim D. S. et al (2009) conducted Exposure and Risk Assessment of BPA on consumption of canned foods in Korean adults, by using HPLC and Fluorescence detection. They found that human exposure level to BPA was well below the tolerable daily intake (TDI) and concluded that the levels of BPA in canned foods are not likely to constitute a safety concern for consumers in Korea.

Muncke J. (2009) reviewed the regulations and use of Endocrine disrupting compounds (EDCs) in food packaging and discussed their presence within the context of new toxicological paradigms. The author also stressed the need of toxicological characterization of nonintentionally added substances (NIAS) in FCMs and dedicated assessment and updating of widespread legal use of EDCs in food packaging according to contemporary scientific knowledge.

In continuation, Muncke J. (2011) also solicited innovations in FCM risk assessment of whole migrate toxicity of food packaging in sensitive population groups viz; women of child bearing age or during pregnancy where a change in the xenobiotics metabolism is observed, indicating the insufficient protection of this group of consumers from current risk assessment practice.

\section{Discussion}

5.1 Common packaging Polymers: Despite various safety concerns, the use of plastics in food packaging has continued to increase due to functional advantages such as Mechanical performance (Tensile strength, Fatigue and abrasion resistance, Transparency, Flexibility), Resistance to weathering or chemical attack (Oxygen, Ozone, Light, Water, Acids/ Bases, Solvents), Processing properties (easily molded/ extruded), Barrier properties $\left(\mathrm{O}_{2}, \mathrm{~N}_{2}\right.$, $\mathrm{CO}_{2}$ ), Electrical properties, Light weight and Cost efficacy. More than 30 types of plastics have been used as packaging materials. The list given below is only illustrative and not exhaustive. 
Table 1: Types of Polymers \& their applications:

\begin{tabular}{|l|l|}
\hline Polymer & Applications \\
\hline $\begin{array}{l}\text { HDPE (High } \\
\text { Pensity }\end{array}$ & $\begin{array}{l}\text { Milk, Water and Juice bottles } \\
\text { Cereal box liners Grocery \& } \\
\text { Retail bags }\end{array}$ \\
\hline $\begin{array}{l}\text { LDPE (Low } \\
\text { Density } \\
\text { Polyethylene) }\end{array}$ & $\begin{array}{l}\text { Domestic cling films Flexible } \\
\text { lids Squeezable food bottles }\end{array}$ \\
\hline $\begin{array}{l}\text { PET (Polyethylene } \\
\text { terphthalate) }\end{array}$ & $\begin{array}{l}\text { Soft drink bottles Jars and tubs } \\
\text { Thermoformed trays \& bags } \\
\text { Snack wrappers }\end{array}$ \\
\hline PP (Polypropylene) & $\begin{array}{l}\text { Heat - resistant microwavable } \\
\text { packaging Sauce /Salad } \\
\text { dressing bottles }\end{array}$ \\
\hline Polycarbonates & $\begin{array}{l}\text { Sterilizable baby bottles } \\
\text { Epoxy-based lacquers inside } \\
\text { metal cans }\end{array}$ \\
\hline $\begin{array}{l}\text { PVC (Polyvinyl } \\
\text { Chloride) }\end{array}$ & $\begin{array}{l}\text { Used with plasticizers } \\
\text { (Phthalates or Adipates) in } \\
\text { commercial grade cling films } \\
\text { for over - wrap of trays }\end{array}$ \\
\hline
\end{tabular}

\subsection{Migration as diffusion-controlled}

process: Chemical migration is mainly diffusion controlled process; Diffusion of chemical substances from polymers into food is a complex process and the extent of migration into another matrix depends on several parameters:

- $\quad$ Physico-chemical properties of the migrant and nature of foodstuff (fatty, acidic or aqueous)

- System Temperature

- Storage time

- Size of packaging in proportion to the food stuff volume

- Concentration of substances in packaging film and food

- Types of components in packaging material

- Pore size, thickness and surface area of contact (Nerin et al, 2013)

The potential influence of FCMs on product safety and quality becomes questionable when their amount in food stuff exceeds their specified limits. The diffusion coefficient of packaging material components increases multifold on exposure to extreme temperature fluctuations (from freezer temperatures to cooking temperature). Elevated temperature and microwave heating increases overall migration or chemical exchange. (Galotto et al, 2004).
5.3 Migrating Components in Plastic Packages: Plastics make getting, eating and storing food more efficient. To make plastics more utilitarian, low molecular weight additives viz. Plasticizers, Antioxidants, Light and Thermal stabilizers, Lubricants are commonly used in different types of polymeric packaging materials. They enhance the performance of polymers during processing and fabrication, reduce the scission and cross-linking of macromolecular chains caused by thermo-oxidative deterioration, increase flexibility, improves thermostability and make them more 'sticky' (for cling film). Small amounts of these additives i.e. unreacted monomers and oligomers may potentially leach into food during cooking or storage. Some common chemical migrants are Styrene, Laurolactam, Limonene, Bisphenol A, Adipates - DEHA i.e. Di-(2-ethyl hexyl) adipate etc.

Recent health controversies have spawned new discussions about the safety of plastics in food industry. Phthalate esters used as plasticizers in the formulation of plastics have been shown to elute at a constant rate and are suspected to be endocrine disruptors (Latini G. et al 2004). Several controversial EDCs like BPA, Triclosan, Nonylphenol, and Phthalates are used in FCMs (Brotons et al, 1995), (Jane M. et al, 2014), (Lopez Espinosa et al, 2007). At low doses, these endocrine disruptors mimic hormone's property to produce systemic effects thus causing subtle changes that may lead to adverse effects at later stages in life (Olea \& Fernandez, 2007).

Perhaps the hottest current debate is regarding the use of epoxy-based resins containing BPA, a colorless water insoluble solid with molecular formula $\mathrm{C}_{15} \mathrm{H}_{16} \mathrm{O}_{2}$ belonging to the group of Diphenylmethane derivatives. It is a synthetic hormone used in hard, clear, lightweight plastics called Polycarbonates, metal can liners, sterilizable baby bottles and water bottles to produce a strong and resilient plastic. Although BPA rose to prominence recently as a potential poison in water bottles, our main exposure comes from the linings of canned foods and food preservatives from plastic bottles and cans lined with Polycarbonate.

5.4 Health Hazards: FCMs have long posed a silent challenge to researchers, nutritionists and environment enthusiasts but until recently with a much lower profile despite being as ubiquitous as particulate air pollution (Jane Muncke et al, 2014). In India, concerns of the people suffering from gastric and renal problems, throat disorders, intestinal cancer, liver dysfunction and infertility are increasing at an alarming rate. Eating hot foods 
carried in plastic bags is the leading cause of these ailments. Drinking tea or any semisolid and liquid food packed in plastic cups make people vulnerable to cancer because plastic can melt due to heat and release carcinogens into the food stuff. Another classical example is keeping the food in freezer along with Ziploc bags and then thawing them. Styrofoam cups are rampantly used in beverage industry, coffee shops and restaurants. Hot coffee, lemon tea or any other acidic beverage may react with Styrofoam cup to form pits as it is softened by Limonene, the principal constituent of lemon oil which is a carcinogenic acyclic terpene.

BPA is also potentially hazardous because it mimics the female hormone estrogen adversely affecting brain and prostate gland in fetuses, infants and children at high exposure levels. Research points out that there are multiple sources of intake of BPA and evidences increasingly suggest that it may act as endocrine disruptor causing detrimental effects even in small doses (Vanderberg et al 2012), (Zoeller et al, 2012).

5.5 Legislation: The fact that humans consuming packaged food are chronically exposed to synthetic chemicals at low concentrations throughout their lives is of huge significance for understanding the life course effects of in-utero and childhood environmental exposures, epigenetics and related processes (Dolinoy et al, 2007) (Feinberg, 2007). Recently, Scientists and regulatory agencies have become concerned about the consumer protection from possible FCM induced toxicity. Hence many countries have formulated their own guidelines and regulations for testing of those substances, specifications about the limit of migration, types of plastics and additives permitted around food packaging and an independent system for performance monitoring and complaint handling procedures.

In order to ensure public safety, Food and Drug Administration (FDA) has identified the types of foods and conditions of use for FCMs and has listed them under the category 'generally recognized as safe' (GRAS). It also provides the guidelines and regulatory aspects for various FCMs and carefully reviews the substances used for packaging. Any substance that can reasonably be expected to migrate into food is classified as an indirect food additive and is subject to FDA regulations. An explicit level of dietary exposure typically inducing toxic effects, thereby posing negligible safety concerns is known as threshold of regulation and may be employed to exempt substances used in FCMs from regulation as food additives. Any new scientific information raising concerns prompts FDA to revisit the threshold level. Furthermore, as per the FDA guidelines, consumers are advised to deploy plastics for intended purposes in accordance with the manufacturer's directions to avoid unintentional safety concerns (Marsh \& Bugusu, 2007).

With the revision of the Food Act, manufacturers, sellers and suppliers need to ensure and show evidence that their FCMs are suitable for the intended use. This might include evidence that their packaging comes from a company that comply with the relevant national or international specifications for packaging safety. Compliance with recognized food standards is reasonable evidence that the materials are suitable for food use.

Although, the fact that no reference populations are completely unexposed to FCMs and hence establishing causality between lifelong and largely invisible exposure to FCMs and chronic diseases is an uphill task, however, progress is urgently needed in population based exposure assessment and biomonitoring of FCMs (Jane M. et al, 2014), (Krishnan K. et al, 2010).

5.6 Risk Mitigation Strategies: Research suggests that proper handling of plastic packages can significantly lower chemical migration.

- Following manufacturer's instructions while using household plastics such as cling films, oven bags, freezer bags and food - storage containers.

- Following recommendations for cleaning products to be used on containers, bottles and lids.

- Using correct type of plastics. Only microwave - safe plastics should be used in microwave oven. Some plastics viz. Margarine containers are not microwave proof as they melt at moderate temperatures.

- Freezing the meat safely in the tray or commercial wrap, but thawing at lower temperature as migration of Di - (2-ethyl hexyl) adipate i.e. DEHA increases with heating in contact with fatty food.

- Reusing food compatible plastic containers.

- Using standard types of supermarket checkout bags in the freezer.

- Refraining from heating food in Supermarket checkout bags. 
- Using eco friendly food baskets instead of plastic casseroles and colorless cotton cloth for wrapping food for long time storage.

\section{Conclusion}

The chemical industry acknowledges that culinary crossing of plastics is inevitable. The amounts may be small but virtually almost any plastic container is expected to leach trace amounts of plastics into food. As the demand for pre-packaged foods increases, so might their potential risk to consumers. Hence, there is an emergent necessity that the migration of chemicals from packaging polymers into foods should be evaluated more strictly in order to ensure that they meet the compliance standards set by regulatory agencies.

Plastic should be avoided for heating and storing food as it produces plethora of health problems. Innovations in FCM risk assessment, apart from routine testing for EDCs are highly recommended. Integrating knowledge about FCM compositions and ECD evaluation into epidemiological studies can also strengthen the primary prevention policies by reducing chemical exposures and advance the applied knowledge on physiological mechanisms linking FCMs to human diseases. The present study also warrants an assessment of the whole migrate toxicity of food packaging materials taking into account all the sensitive population groups.

\section{Acknowledgment}

Author would like to thank Smt. C.H.M College for research assistance as well as for providing opportunity and facilities required for completing the present research work.

\section{References}

[1] Brotons J. A.; Olea Serrano M. F.; Villalobos M.; Xenoestrogens released from lacquer coatings in food cans. Environ Health Perspect. 103(6): 608-12 (1995).

[2] Dolinoy D. C.; Huang D.; Jirtle R. L.; Maternal nutrient supplementation counteracts Bisphenol A induced DNA hypomethylation in early development. Proc. Natl. Acad. Sci. USA, 104(32): $10356-61$ (2007).
[3] Feinberg A. P.; Phenotype plasticity and the epigenetics of human disease. Nature, 447: 433-40 (2007).

[4] Galotto M. J.; Guarda A.; Suitability of alternative fatty food simulants to study the effect of thermal and microwave heating on overall migration of plastic packaging. Packaging Technology and Science, 17 (4): 219-23 (2004).

[5] Goulas, A. E.; Anifantaki K. I.; Kolioulis D. G.; Kontominas M., Migration of Di - (2-ethylhexylexyl) Adipate Plasticizer from Food-Grade Polyvinyl Chloride Film into Hard and Soft Cheeses. Journal of Dairy Science, 83 (8): 1712-18 (2000).

[6] Grob K.; Biedermann M.; Scherbaum E.; Roth M., Rieger K., Food contamination with organic materials in perspective: packaging materials as the largest and least controlled source? A view focusing on the European situation. Crit. Rev. Food Sci. Nutr., 46(7): 529-536 (2006).

[7] Jane Muncke; John Peterson Myers; Martin Scheringer; Miquel Porta, Food packaging and migration of food contact materials: Will epidemiologists rise to the neotoxic challenge? Journal of Epidemiology and Community Health, 68 (7): 592-94 (2014).

[8] Krishnan K., Gagne M., Nong A., Aylward L. L., Hays S. M., Biomonitoring equivalents for Bisphenol A (BPA). Regul Toxicol Pharmacol, 58 (1): 18-24 (2010).

[9] Latini Giuseppe; Alberto Verrotti; Claudio De Felice; Di - (2-ethylhexyl) phthalate and endocrine disruption: A review. Current Drug Targets: Immune Endocrine Metabolic Disorders, 4(1): 37-40 (2004).

[10] Lim D. S.; Kwack S. J; Kim K. B.; Kim H. S., Lee B. M.; Risk Assessment of Bisphenol A in canned foods in Korea. J Toxicol Environ Health, 72 $(21-22)$ : 1327-35 (2009).

[11] Lopez Espinosa M. J.; Granada A.; Araque P., et al; Oestrogenecity of paper and cardboard extracts used as food containers. Food Additives and Contaminants, 24(1): 95-102 (2007).

[12] Marsh, Kenneth and Bugusu Betty; Food Packaging - Roles, Materials and Environmental issues. Journal of Food Science, 72 (3): R39-R55 (2007). 
[13] Muncke J. Exposure to endocrine disrupting compounds via the food chain: Is packaging a relevant source? Sci. Total Environ. 407(16): 454959 (2009).

[14] Muncke J.; Endocrine disrupting chemicals and other substances of concern in food contact materials: an updated review of exposure, effect and risk assessment. J. Steroid Biochem Mol. Biol., 127(1-2): 118-127 (2011).

[15] Nerin C.; Alfaro P.; Aznar M.; et al; The challenge of identifying nonintentionally added substances from food packaging materials: A review. Analytica Chimica Acta., 775: 14-24 (2013).

[16] Olea N.; Fernandez M. F; Endocrine disruption. Journal of Epidemiology \& Community Health, 61(5): 372-73 (2007).
[17] Sara J. Risch Food Packaging History and Innovations. Journal of Agricultural and Food Chemistry, 57(18): 8089 -8092 (2009).

[18] Thompson B. M.; and Grounds P. R.; Bisphenol A in canned food in New Zealand: An exposure assessment. Food Additives and Contaminants, 22 (1): 65-72 (2005).

[19] Vanderberg L. N.; Colborn T.; Hayes T. B.; et al; Hormones and endocrine disrupting chemicals: low dose effects and nonmonotonic dose responses. Endocrine Reviews, 33(3): 378-455 (2012).

[20] Zoeller R. T.; Brown T. R.; Doan L. L.; et al Endocrine disrupting chemicals and public health Protection: A statement of Principles from the endocrine society. Endocrinology, 153(9): 4097-110 (2012). 